\title{
Simultaneous Determination of REEs in Coal Samples Using the Combination of Microwave-Assisted Ashing and Ultrasound-Assisted Extraction Methods Followed by ICP-OES Analysis
}

\author{
Mceliseni C. Zuma ${ }^{1}$, Philiswa N. Nomngongo ${ }^{2}\left(\mathbb{D}\right.$ and Nomvano Mketo ${ }^{1, *}$ \\ 1 Department of Chemistry, College of Science and Engineering and Technology, Florida Science Campus, \\ University of South Africa, Johannesburg 1709, South Africa; 55650163@mylife.unisa.ac.za \\ 2 Department of Chemical Sciences, University of Johannesburg, Johannesburg 2028, South Africa; \\ pnnomngongo@uj.ac.za \\ * Correspondence: mketon@unisa.ac.za; Tel.: +27-114712032
}

\section{check for} updates

Citation: Zuma, M.C.; Nomngongo, P.N.; Mketo, N. Simultaneous

Determination of REEs in Coal Samples Using the Combination of

Microwave-Assisted Ashing and Ultrasound-Assisted Extraction Methods Followed by ICP-OES Analysis. Minerals 2021, 11, 1103. https://doi.org/10.3390/min11101103

Academic Editors: Benjamin P. Wilson and Xianping Luo

Received: 29 August 2021

Accepted: 5 October 2021

Published: 8 October 2021

Publisher's Note: MDPI stays neutral with regard to jurisdictional claims in published maps and institutional affiliations.

Copyright: (c) 2021 by the authors. Licensee MDPI, Basel, Switzerland. This article is an open access article distributed under the terms and conditions of the Creative Commons Attribution (CC BY) license (https:// creativecommons.org/licenses/by/ $4.0 /)$.

\begin{abstract}
The world during the COVID-19 pandemic has led to extensive use of virtual activities by means of electronic devices, which are made up of rare earth elements (REEs). This means that quantitative knowledge of REEs in various resources is crucial for the development of effective recovery methods. Therefore, this report describes a simple microwave assisted ashing followed by ultrasound-assisted extraction (MAA-UAE) for quantitative determination of REEs in coal samples using inductively coupled plasma-optical emission spectroscopy (ICP-OES). Firstly, coal samples were ashed at $55^{\circ} \mathrm{C}$ for $4.5 \mathrm{~h}$ to form white ashes, which were then treated with dilute $\mathrm{HNO}_{3}$ acid under ultrasonication to enhance the extraction of REEs. The quantitative recoveries (86-120\%) of REEs were obtained when $1 \mathrm{~mol} \mathrm{~L}-1,0.1 \mathrm{~g}, 40{ }^{\circ} \mathrm{C}, 20 \mathrm{~min}$, and high frequency were applied for $\left[\mathrm{HNO}_{3}\right]$, sample mass, ultrasonic bath temperature, extraction time, and ultrasonic bath frequency, respectively. The method detection limits of the proposed MAA-UAE method were between 0.0075 and $0.59 \mu \mathrm{g} \mathrm{g}^{-1}$ with satisfactory precision $(<5 \%)$. The concentration levels of REEs in South African coals ranged from 1.4 to $105 \mathrm{\mu g} \mathrm{g}^{-1}$, suggesting that this coal can be a resource for REEs.
\end{abstract}

Keywords: microwave-assisted ashing; ultrasound-assisted extraction; rare earth elements; inductively coupled plasma-optical emission spectroscopy; coal

\section{Introduction}

Rare earth elements (REEs) consist of 15 lanthanides as well as yttrium and scandium. These elements have been recognized as important commodities by several international agencies and national governments [1,2]. Due to their unique magnetic, phosphorescent, and catalytic properties, REEs are the critical and irreplaceable materials in modern technologies (TVs, cellular phones, computers, permanent magnet motors for wind turbines and disk drives, hybrid car batteries, compact fluorescent lighting, catalysts for refining heavier crude oil, automobile catalytic converters, etc.) [3]. Additionally, the COVID-19 pandemic has forced extensive use of virtual/online activities by using electronic devices made up of REEs. This means that, there is a rapid increase in REEs applications, and more resources are currently required [1]. Therefore, quantitative knowledge of REEs present in coal is vital for developing effective extraction methods for their recovery $[1,4]$.

The first report on quantitative analysis of REEs in coal was published in 1993 and it was observed that REEs were mostly associated with silicate minerals and positively linked with the main components of ash (aluminium, iron, and sodium) [5]. The mostly reported spectrometric techniques for the determination of REEs in several samples are inductively coupled plasma-mass spectrometry (ICP-MS) and inductively coupled plasmaoptical emission spectrometry (ICP-OES) [6]. However, ICP-MS is the most preferred 
technique, because of its high sensitivity, which resulted in low detection limits [7,8]. The only disadvantage with ICP-MS is that, it is costly and requires sophisticated operational management [9]. Therefore, ICP-OES is the technique of choice in a developing country like South Africa. However, this technique requires sample preparation steps before multi-elemental analysis in complex matrices [10]. Thus, solid samples like coal should be completely dissolved and digested prior to elemental analysis [11]. Usually, sample preparation is performed by a conventional hotplate or microwave-assisted digestion [12]. These digestion methods are normally conducted using concentrated inorganic acids $\left(\mathrm{HNO}_{3}\right.$, $\mathrm{HCl}, \mathrm{HF}, \mathrm{H}_{2} \mathrm{SO}_{4}, \mathrm{HClO}_{4}$ ) and/or in combinations with hydrogen peroxide [12,13]. However, some of these acids release carcinogenic gasses, have safety concerns, can dissolve glass optics of spectrometric techniques, and can cause matrix effects during ICP-OES analysis [14]. Therefore, to solve such challenges, some researchers have demonstrated the use of dilute acids. Several investigations indicated the use of diluted inorganic acids for extraction of trace elements in solid matrices, with recoveries of $89-117 \%$, as a result of the increased interest in implementing 'Green Chemistry' principles [15]. Another impressive study reported development of a greener microwave-assisted hydrogen peroxide digestion (MW-AHPD) for multi-elemental determination in coal samples using spectrometric techniques. For 18 elements, excellent precision (3.1 percent) and accuracy (92-114 percent) were achieved. Due to the diluted acid utilized, accepted method detection limits (0.003-3.5 $\left.\mathrm{\mu g} \mathrm{g}^{-1}\right)$ were achieved. [10].

Other methods that have been reported to reduce the use of concentrated acid are ultrasound-assisted extraction (UAE) [16,17]. There are many studies that have investigated the use of UAE on coal matrices. For example, Suzana et.al. [18], developed an analytical method for the extraction of selected trace elements from coal samples using $\mathrm{HNO}_{3}$ medium, followed by ICP-OES. The results indicate that there was good agreement between the certified or reported values and the values obtained by hot extraction in nitric acid for most elements; the exception was V in SARM 18, SARM 19, and SARM 20, which had recoveries of 78,72 , and $62 \%$, respectively. RDSs ranged from $0.4 \%$ to $22.8 \%$. Another interesting study was reported by Fernanda and co-workers for the determination of $\mathrm{Co}, \mathrm{Cr}$, $\mathrm{Cu}, \mathrm{Fe}, \mathrm{Mn}, \mathrm{Ni}, \mathrm{Ti}, \mathrm{V}$, and $\mathrm{Zn}$ in coal fly ashes using UAE followed by ICP-OES. The detection limits ranged from 0.06 to $4.3 \mathrm{~g} \mathrm{~g}^{-1}$, with recoveries $\geq 81 \%$ [18]. Nascentes et al. [19], applied UAE in plant material under optimal conditions $\left(0.14 \mathrm{~mol} \mathrm{~L}{ }^{-1} \mathrm{HNO}_{3}, 10 \mathrm{~min}\right.$ and a particle size $<75 \mu \mathrm{m}$ ) and recoveries ranging from 96 to $102 \%$ were obtained for $\mathrm{Ca}, \mathrm{Mg}, \mathrm{Mn}$ and $\mathrm{Zn}$. Therefore, UAE methods are inexpensive, simple, reliable, and can be effective alternatives to conventional extraction methods [20]. Additionally, UAE are also considered environmentally friendly methods, because of their lower energy levels $\left(\leq 80^{\circ} \mathrm{C}\right)$ and since greener solvents are mostly used [21].

Therefore, the purpose of this study was to develop a cost-effective, rapid, environmentally friendly, simple, and effective sample preparation method based on the use MAA combined with UAE for quantitative determination of REEs in coal samples using ICP-OES. The optimization of the crucial parameters such as $\left[\mathrm{HNO}_{3}\right]$, sample mass, extraction time, ultrasonic bath temperature, and ultrasonic bath frequency were carried out using certified reference material (SARM 19). However, the other CRMs (SARMs 18 and 20) were used for validation purposes.

\section{Materials and Methods}

\subsection{Instrumentation}

Coal samples were weighed into $30 \mathrm{~mm}$ Coors crucibles using an electronic balance (ML204, METTLER TOLEDO, Poway, CA, USA). A microwave-assisted ashing system (PYROXL, milestone) was used for ashing of coal samples. An ultrasound-assisted extraction (4 litre, SCIENTECH ultrasonic cleaner, model: 702, Johannesburg, South Africa) was used to extract REEs in ashed samples and the analysis of REEs was performed by using ICP-OES (Agilent Technologies 700 series ICP OES, Melboume, Australia) for all CRMs and real coal samples. During ICP-OES analysis, the samples were introduced with a concentric 
nebulizer and a cyclonic spray chamber. The operating parameters of the instrument are presented in Table 1.

Table 1. ICP-OES operating conditions.

\begin{tabular}{cc}
\hline Parameters & Conditions \\
\hline RF generator power $(\mathrm{kW}):$ & 1.20 \\
Plasma flow (L/min): & 15.0 \\
Nebulizer (L/min): & 0.75 \\
Replication reding time (s): & 1.0 \\
Auxiliary gas (L/min): & 1.50 \\
Instru stabilization delay (s): & 15 \\
Pump rate (rpm) & 15 \\
Sample uptake delay (s): & 30 \\
Replicates: & 3 \\
Flush time (s): & 10 \\
& Ce $(418.659 \mathrm{~nm}), \mathrm{Eu}(397.197 \mathrm{~nm}), \mathrm{Er}(361.265 \mathrm{~nm}), \mathrm{Gd}$ \\
Wavelengths (nm): & $(358.496 \mathrm{~nm}), \mathrm{Ho}(347.425 \mathrm{~nm}), \mathrm{La}(333.749 \mathrm{~nm}), \mathrm{Lu}$ \\
& $(219.556 \mathrm{~nm}), \mathrm{Nd}(401.224 \mathrm{~nm}), \mathrm{Pr}(390.843) \mathrm{Sc}$ \\
& $(357.634 \mathrm{~nm}), \mathrm{Sm}(442.434 \mathrm{~nm}), \mathrm{Tb}(350.914 \mathrm{~nm}), \mathrm{Tm}$ \\
& $(349.919 \mathrm{~nm}) \mathrm{Y}(320.027 \mathrm{~nm}), \mathrm{Yb}(218.572 \mathrm{~nm})$ \\
\hline
\end{tabular}

\subsection{Samples, Reagents, and Standards}

Coors crucibles were soaked in $\mathrm{HNO}_{3}$ acid $\left(5 \mathrm{~mol} \mathrm{~L}^{-1}\right)$ overnight and then placed in an oven at $100{ }^{\circ} \mathrm{C}$ prior to use. The extraction efficiencies were evaluated by using coal certified reference materials (SARMs 18, 19, and 20) with particle sizes of $\leq 106 \mu \mathrm{m}$ obtained from Mintek (Johannesburg, South Africa). During the optimization step, however, only one CRM (SARM 19) was employed because it contained the majority of the REEs and was reported to have been sampled from the Orange Free State, Republic of South Africa. For further validation, the other two CRMs (SARM 18, sampled from Witbank and SARM 20, sampled from Sasolburg) were investigated. Coal samples with unknown REEs content levels were obtained from one of South African coal mines and labelled as coal samples A, B, and C. Moreover, the three coal samples with unknown REEs concentration content were obtained from one of the South African coal mines. These coal samples were milled and sieved to ensure comparable particle size $(\leq 106 \mu \mathrm{m})$ with CRMs.

Ultra-pure water $\left(18 \mathrm{M} \Omega \mathrm{cm}^{-1}\right)$ from a Milli-Q water purification system (Milli-Q SP ICP-MS, Millipore, Burlington, MA, USA) and ACS grade $\mathrm{HNO}_{3}$ acid (70\%) (purchased from Sigma-Aldrich, Johannesburg, South Africa) were used in all extraction experiments. Rare-earth elemental quantification by ICP-OES was carried out using external calibration standards which ranged from $0.2,0.4,0.6,0.8,1.0,1.5$ and $2.0 \mathrm{ppm}$. These calibration standards were prepared from $50 \mathrm{mg} \mathrm{L}^{-1}$ multi-elemental (Sc, Y, La, Pr, Nd, Sm, Eu, Gd, Tb, $\mathrm{Dy}, \mathrm{Ho}, \mathrm{Er}, \mathrm{Tm}, \mathrm{Yb}$, and Lu) stock solution (purchased from Sigma-Aldrich, South Africa) to accommodate all the different REEs under investigation.

\subsection{Microwave-Assisted Ashing (MAA) Procedure}

The microwave-assisted ashing method was adapted from the previously published literature report [22], with some alterations in ramping time. This method was utilized to eliminate carbon content from coal. To describe the procedure briefly, approximately, $2.0 \mathrm{~g}$ of coal was carefully weighed, transferred into six $30 \mathrm{~mL}$ Coors crucibles, and placed in an MAA system. The operating program for the microwave ashing of coal samples is shown in Table 2. After cooling to room temperature, white ash residues were weighed to get weight loss and were stored in a desiccator. 
Table 2. Microwave assisted ashing program.

\begin{tabular}{cccc}
\hline Step & Temperature $\left({ }^{\circ} \mathbf{C}\right)$ & Ramping Time (hours) & Hold (min) \\
\hline 1 & 380 & 2 & 30 \\
2 & 550 & 1 & 50 \\
\hline
\end{tabular}

\subsection{Ultrasound-Assisted Extraction Procedure}

The most used acid for mineralization of organic matrices is $\mathrm{HNO}_{3}$ [23]. This is because, $\mathrm{HNO}_{3}$ has attractive features such as oxidizing capacity, easy accessibility, affordability, and compatibility to metal ions and spectroscopic techniques [24,25]. Therefore, a known amount of the ashed coal sample was accurately weighed and transferred into $15 \mathrm{~mL}$ centrifuge tubes, followed by dilute $\mathrm{HNO}_{3}$. The addition of the dilute acid was conducted to facilitate the extraction of REEs. Then, the REEs extraction was enhanced by using ultrasonic bath and colourless supernatant was separated from the white solid residues by using centrifugation for $15 \mathrm{~min}$ at $3000 \mathrm{rpm}$. Then, each sample was filtered through 0.45-micrometer tetrafluoroethylene membrane filter (Millipore, Burlington, MA, USA) into $10 \mathrm{~mL}$ volumetric flask, and filled to the mark with distilled water before determination of REEs by ICP-OES. Each sample was prepared and processed in replicates $(n=3)$ to measure precision. The percentage recovery of each element was calculated using Equation (1) and it was compared with the certified values in the certified reference material (CRM).

$$
\% \text { Recovery }=\frac{\text { Experimental value }}{\text { CRM value }} \times 100 \%
$$

where CRM value is the certified value on the CRM certificate and the experimental value is the value calculated from ICP-OES measurements and the final dilution factor of the extraction.

Ultrasonic assistant extraction efficiencies were examined by calculating quantitative recoveries of REEs in CRMs and five experimental parameters were evaluated. The investigated parameters include $\left[\mathrm{HNO}_{3}\right]\left(1-5 \mathrm{~mol} \mathrm{~L}^{-1}\right)$, sample mass $(0.1-0.5 \mathrm{~g})$, UAE temperature $\left(20-80^{\circ} \mathrm{C}\right)$, extraction time (5-30 min), and UAE frequency (high and low). The volume of the extraction solution was kept consistent $(8 \mathrm{~mL})$ throughout the optimization.

\section{Results and Discussion}

\subsection{Effect of the $\mathrm{HNO}_{3}$ Acid Concentration during UAE of REEs in Coal}

According to the previous literature reports, it was observed that the concentration of the extracting reagent is one of the most significant parameters that affect UAE extraction efficiencies [26]. This is because the additional acids enhance extraction and serve as eluent for metal ions that would otherwise be attached to the surface of solid residue. Furthermore, other studies have shown that without an acid eluent, low percentage recoveries can be achieved [10]. Consequently, the proposed method was optimized by firstly examining the effect of the five different $\mathrm{HNO}_{3}$ concentration levels $\left(1,2,3,4\right.$, and $\left.5 \mathrm{~mol} \mathrm{~L}{ }^{-1}\right)$, while other factors were held constant. The obtained outcomes for this examination are illustrated in Figure 1. From this figure, it can be observed that an increase in $\mathrm{HNO}_{3}$ concentration improved extraction recoveries of all investigated REEs and a slight decreased was noticed for higher concentration levels $\left(4-5 \mathrm{~mol} \mathrm{~L}^{-1}\right)$. Additionally, at low $\mathrm{HNO}_{3}$ concentration levels $\left(1 \mathrm{~mol} \mathrm{~L}^{-1}\right)$, the extraction efficiencies were within 99 to $108 \%$, which makes the developed method to be greener as compared to $3 \mathrm{~mol} \mathrm{~L}^{-1} \mathrm{HNO}_{3}$. It is worth noting that, analyte recoveries greater than $100 \%$ have been observed for REEs elements ranging between $94-110 \%$ [27], 91-117\% [28], 86-119\% [28], and 92-112\% [29]. Thus, $1 \mathrm{~mol} \mathrm{~L}^{-1}$ $\mathrm{HNO}_{3}$ concentration was selected as the optimum level to guarantee the total release of the remaining REEs binding to the white solid residues of the coal. Furthermore, the optimum concentration level was applied for optimization of other parameters prior to REEs analysis by ICP-OES. 


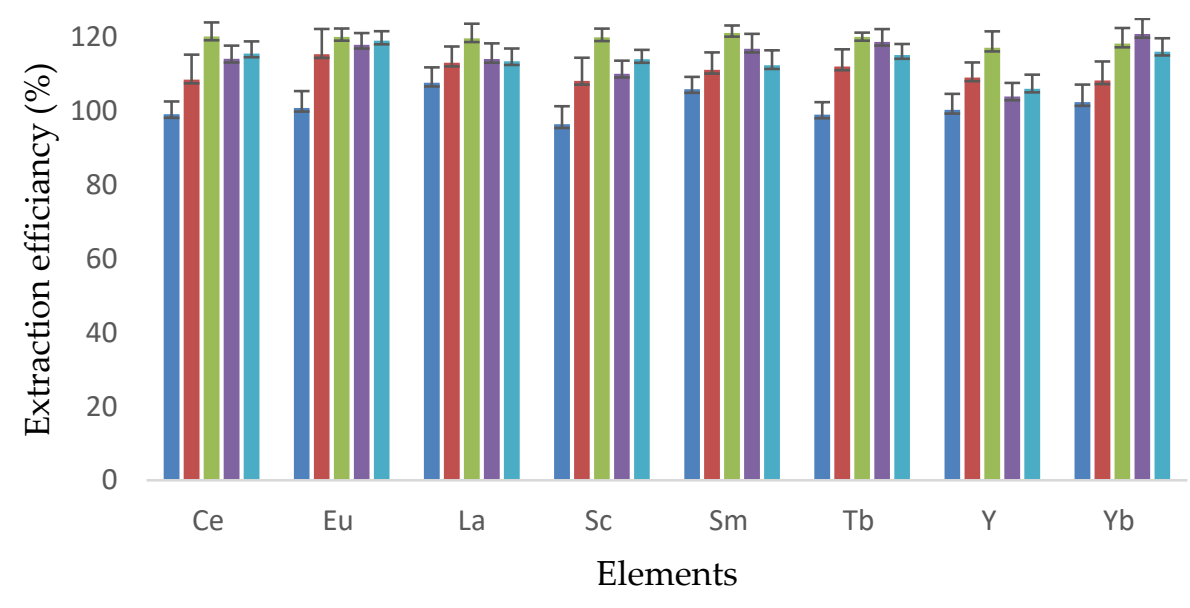

$\square 1 \mathrm{M}-2 \mathrm{M}-3 \mathrm{M}-4 \mathrm{M}-5 \mathrm{M}$

Figure 1. Effects of different $\mathrm{HNO}_{3}$ concentrations $\left(1-5 \mathrm{~mol} \mathrm{~L}^{-1}\right)$ for the extraction of REEs in coal samples. UAE conditions: $\left[\mathrm{HNO}_{3}\right]$ (optimized), sample mass $(0.1 \mathrm{~g})$, extraction time (30 min), UAE temperature $\left(80^{\circ} \mathrm{C}\right)$, UAE frequency (high) and replicates $(n=3)$.

\subsection{Effect of Sample Weight during UAE of REEs in Coal}

The influence of sample amount $(0.1,0.2,0.3,0.4$, and $0.5 \mathrm{~g})$ was also investigated for the UAE of REEs and the results are illustrated in Figure 2. It has to be noted that coal sample mass of $0.05 \mathrm{~g}$ was previously studied by our colleagues, and it resulted in poor precision $(>7 \%)$ [30], hence the optimization of sample mass started at $0.1 \mathrm{~g}$ for the current study. The results shown in Figure 2 illustrate that as the coal amount increases the extraction efficiencies decreased for all the investigate REEs, indicating that the coal amount is an influential factor. This type of results pattern is comparable to what was observed in other literature reports $[10,25]$. This is due to the fact that, when the amount of coal increases, the extracting reagent approaches saturation point. Hence, for the current study, $0.1 \mathrm{~g}$ showed better extraction recoveries (90-120\%) for targeted REEs. The optimum condition of the sample amount $(0.1 \mathrm{~g})$ was then used in all the subsequent experiments.

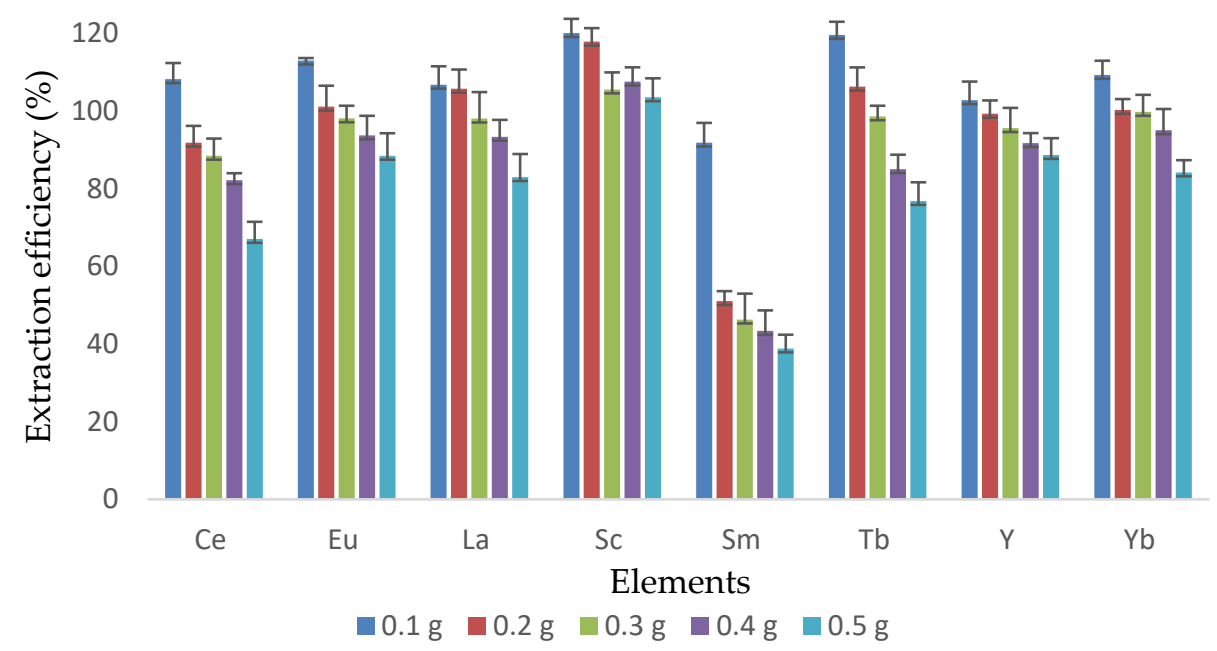

Figure 2. Effects of different masses (0.1-0.5 g) for the extraction of REEs in coal samples. UAE conditions: $\left[\mathrm{HNO}_{3}\right]\left(1 \mathrm{~mol} \mathrm{~L}^{-1}\right)$, sample mass (optimized), extraction time (30 min), UAE temperature $\left(80^{\circ} \mathrm{C}\right)$, UAE frequency (high), and replicates $(n=3)$. 


\subsection{Effect of the Time during UAE of REEs in Coal}

Since a less time-consuming sample preparation technique which also minimizes energy is desirable, the extraction time $(5,10,20$, and $30 \mathrm{~min})$ was explored [31]. The outcomes for the investigated factor are shown in Figure 3. From the figure below it can be observed that the quantitative extraction efficiencies of REEs were influenced by the extraction duration, as the longer extraction time achieved higher extraction recoveries. However, quantitative extraction efficiencies at the extraction time of $20 \mathrm{~min}$ proved to be the optimal time for eight of the targeted REEs with recoveries ranging from 90 to $115 \%$, in comparison to $5 \mathrm{~min}(44-99 \%)$ and $10 \mathrm{~min}(68-104 \%)$. Additionally, the shorter the extraction time, the lesser the energy used for extraction and greener the method, hence higher UAE times were not studied. Therefore, the optimum time of $20 \mathrm{~min}$ was selected and applied for further optimization.

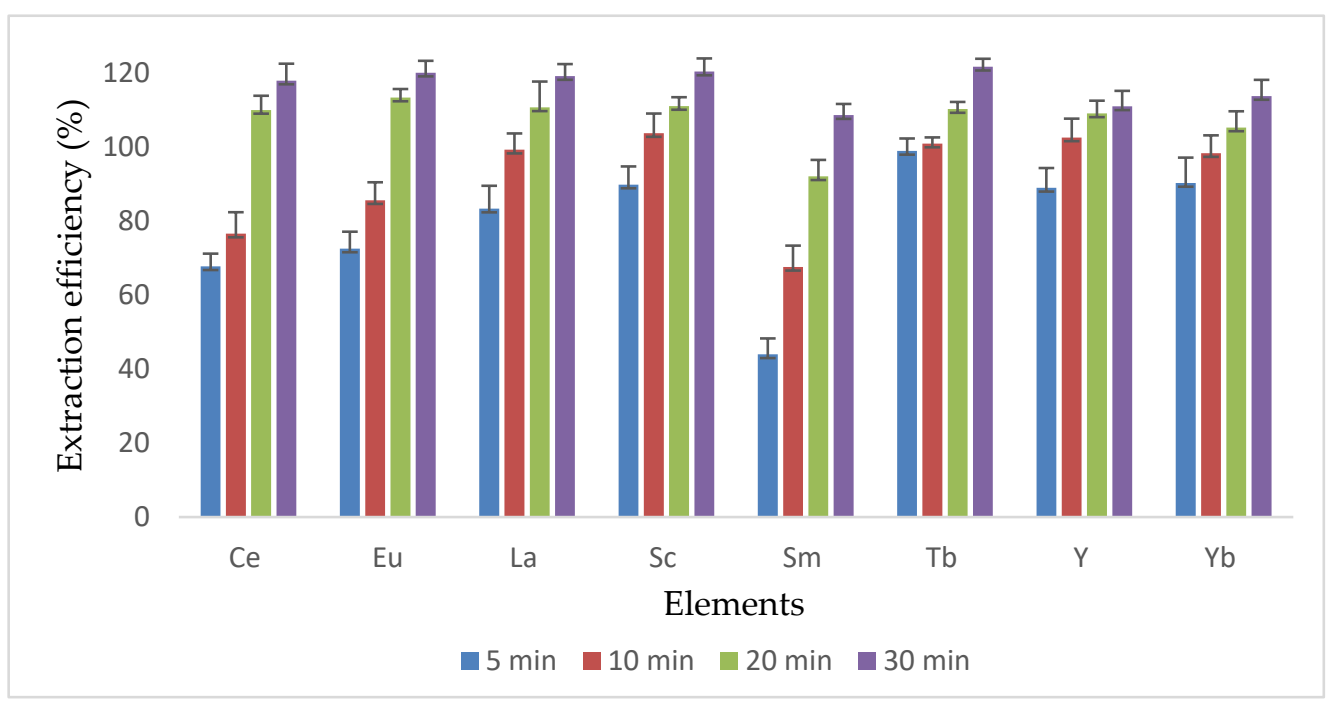

Figure 3. Effects of different ultrasound extraction times $(5,10,20$, and $30 \mathrm{~min})$ for the extraction of REEs in coal samples. UAE conditions: $\left[\mathrm{HNO}_{3}\right]\left(1 \mathrm{~mol} \mathrm{~L}{ }^{-1}\right)$, sample mass $(0.1 \mathrm{~g})$, extraction time (optimized), UAE temperature $\left(80^{\circ} \mathrm{C}\right)$, UAE frequency (high), and replicates $(n=3)$.

\subsection{Effect of Temperature during UAE of REEs in Coal}

Temperature can increase extraction recoveries by influencing properties such as viscosity, diffusivity, solubility, and surface tension [32]. The influence of four ultrasonic bath temperatures $\left(20,40,60\right.$, and $\left.80^{\circ} \mathrm{C}\right)$ on the REEs extraction were investigated and the outcomes are illustrated in Figure 4. From this figure, it can be observed that an increase in temperature improved the quantitative extraction recoveries of REEs from coal samples. The recoveries of REEs increased linearly with increasing temperature from 20 to $80{ }^{\circ} \mathrm{C}$. Higher temperatures can accelerate molecular movements and increase the conductivity of the solution to sample. This effect increases the solubility and diffusivity of the samples in solution, thereby increasing the extraction recoveries. Furthermore, at higher temperatures, solvents have a greater capacity to solubilize analytes, while surface tension and solvent viscosity decrease, improving sample wetting matrix penetration [33]. All the experiments carried out at low temperatures $\left(20^{\circ} \mathrm{C}\right)$ resulted in moderate extraction efficiencies (60-103\%) in some of the REEs. Additionally, it can be observed that $40{ }^{\circ} \mathrm{C}$ showed an improved extraction efficiency for all the eight tested REEs with recoveries ranging between 90 and $110 \%$. When the extraction temperature was $60{ }^{\circ} \mathrm{C}$, the REEs extraction recoveries ranged between 109 and $117 \%$. The extraction recoveries increased significantly at $60{ }^{\circ} \mathrm{C}$, as evidenced by an increase in total REEs extraction recoveries ranging between 118 and $123 \%$. Therefore, $40{ }^{\circ} \mathrm{C}$ was selected as the optimum temperature for the proposed UAE. 


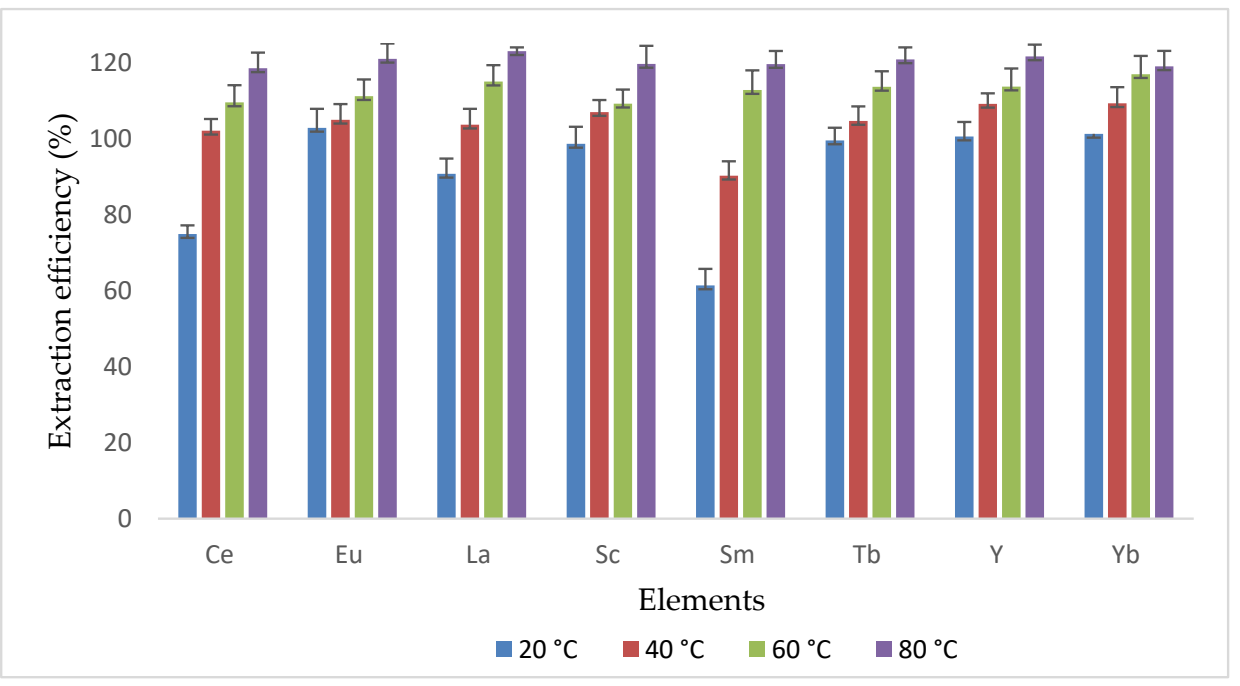

Figure 4. Effects of different ultrasound extraction temperatures $\left(20,40,60\right.$, and $\left.80{ }^{\circ} \mathrm{C}\right)$ for the extraction of REEs in coal samples. UAE conditions: [HNO 3 ] $\left(1 \mathrm{~mol} \mathrm{~L}^{-1}\right)$, sample mass $(0.1 \mathrm{~g})$, extraction time (20 min), UAE temperature (optimized), UAE frequency (high), and replicates $(n=3)$.

\subsection{Effect of Ultrasound Frequency during UAE of REEs in Coal}

The effect of low and high frequencies was also investigated for the UAE of REEs in coal. The results for investigated frequencies at a fixed reagent volume $(8 \mathrm{~mL})$, under optimum conditions are shown in Figure 5. These results reveal that the two different frequencies of the ultrasound device have varying effects on the targeted REEs in coal. The high frequency showed high recoveries (99 and 120\%) of the REEs compared to low frequency $(66-120 \%)$. Hence, the high frequency was selected as the optimal frequency. In 2015, Lios at. el. [34], evaluated the optimal conditions that influenced ultrasound extraction of lycopene from tomatoes. The optimal conditions were extraction time duration ( $20 \mathrm{~min}$ ); ratio of solvent to material $(2: 1)$; extraction temperature $\left(25^{\circ} \mathrm{C}\right)$; ultrasonic power $(200 \mathrm{~W})$; and ultrasonic frequency $(46-48 \mathrm{kHz})$. Ultrasound frequency of $5 \mathrm{kHz}$ was discovered to be the optimum level for the extraction of betulin from B. papyfera bark [35]. Wang and co-workers conducted a studied on the optimization of UAE conditions of cordycepin from codyceps militaris and quantitative recoveries $(86.98 \pm 0.23 \%)$ at $56 \mathrm{kHz}$ frequency [36]. The trend from some the UAE experiments shows that lower frequencies require longer extraction periods for the targeted analytes.

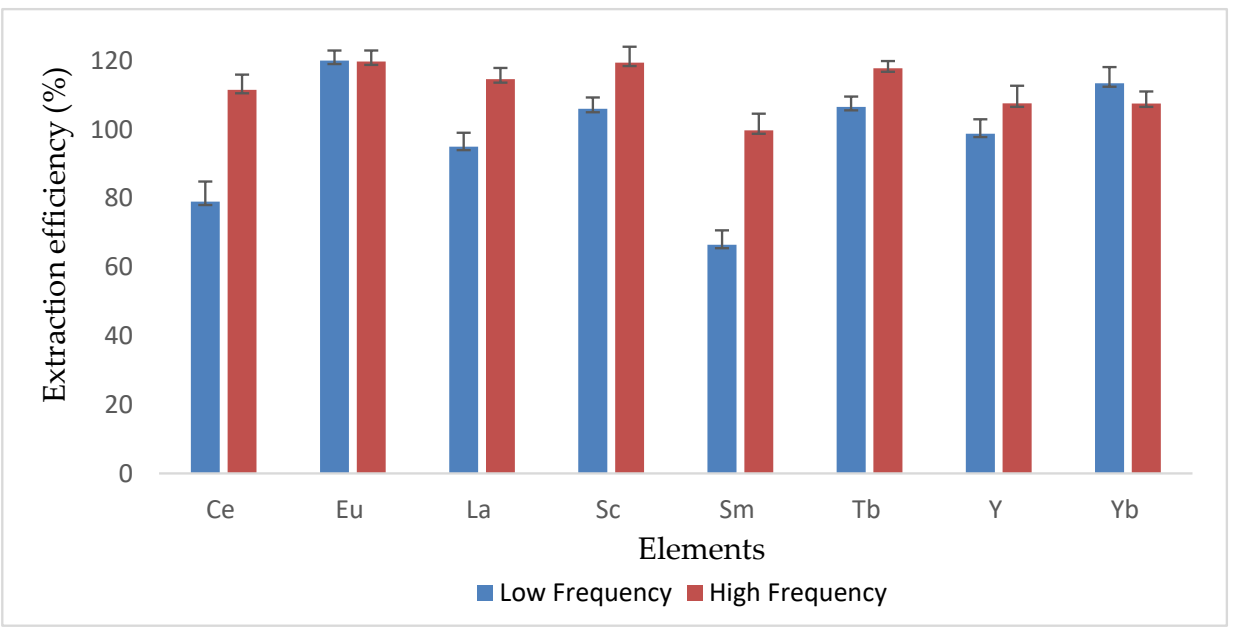

Figure 5. Effects of different ultrasound frequencies (low and high) for the extraction of REEs in coal samples. UAE conditions: $\left[\mathrm{HNO}_{3}\right]\left(1 \mathrm{~mol} \mathrm{~L}^{-1}\right)$, sample mass $(0.1 \mathrm{~g})$, extraction time $(20 \mathrm{~min}), \mathrm{UAE}$ temperature $\left(80^{\circ} \mathrm{C}\right)$, UAE frequency (optimized), and replicates $(n=3)$. 


\subsection{Validation of the MAA-UAE Method \\ 3.6.1. Accuracy}

After the optimization step, the optimum conditions of the proposed MAA-UAE method were utilized for validation purposes. Accuracy (agreement) of the MAA-UAE method was performed to ensure that in future routine analysis, the concentration levels of the target analytes are close enough to the true in the unknown sample. Therefore, three coal CRMs (SARMs 18, 19, and 20) were subjected to the optimum conditions and the resulting extracts were analysed for REEs by using ICP-OES. The results (Figure 6) on the accuracy of the proposed method demonstrated that the targeted REEs concentration levels are in good agreement ( 86 and $120 \%$ ) with the certified values except for SARM 20, where low recoveries $(\leq 90 \%)$ were obtained.

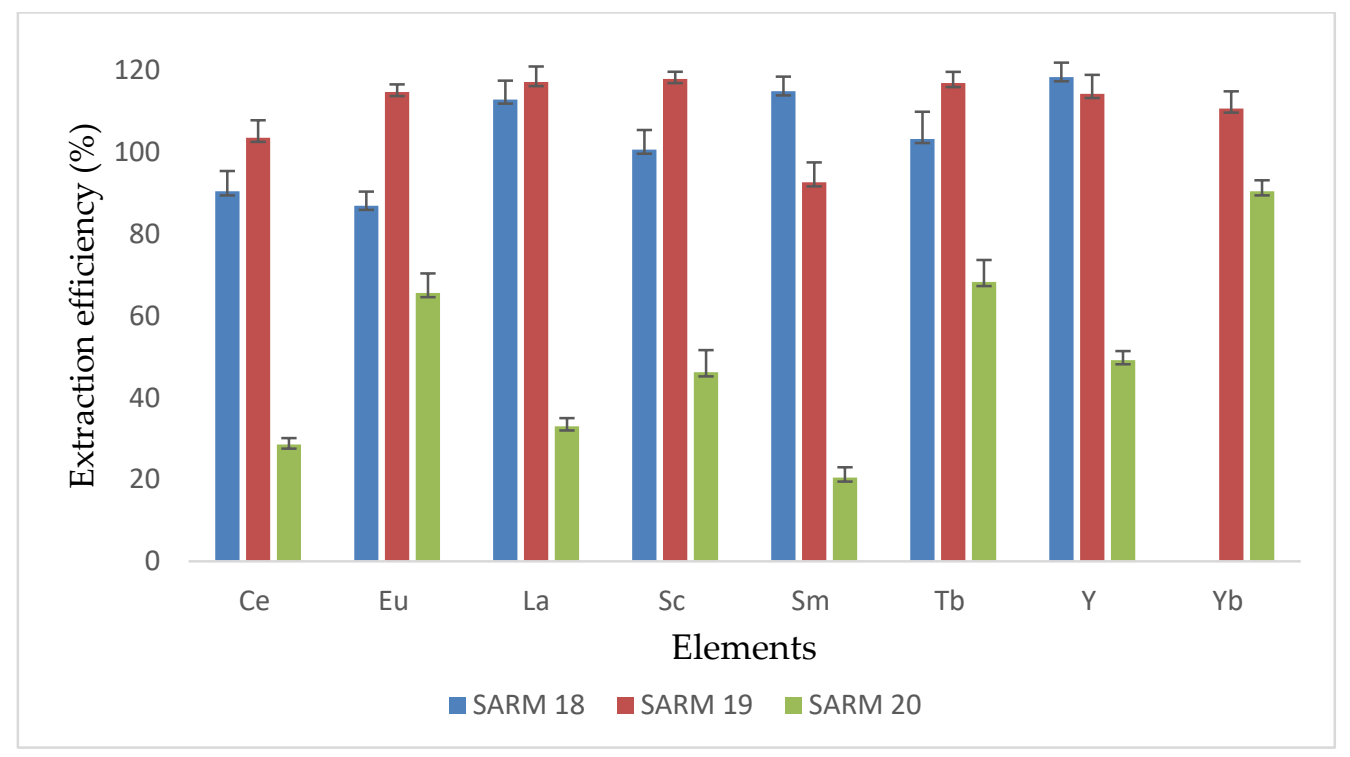

Figure 6. ICP-OES analytical results of REEs in SARM 18, 19, and 20 after MAA-UAE with a dilute $\mathrm{HNO}_{3}$ solution: UAE conditions: $\left[\mathrm{HNO}_{3}\right]\left(1 \mathrm{~mol} \mathrm{~L}^{-1}\right)$, sample mass $(0.1 \mathrm{~g})$, extraction time (20 min), $\mathrm{UAE}$ temperature $\left(80^{\circ} \mathrm{C}\right)$, UAE frequency (high), and replicates $(n=3)$.

It is worth noting that after MAA, coal samples showed decrease in weight as shown in Table 3. From this table it can be observed that SARM 20 showed the lowest weight loss $(50 \%)$, followed by SARM $19(63 \%)$, then SAMR $18(76 \%)$. These results imply that SARM 18 contains more carbon content that SARMs 19 and 20 and these findings agree with the information recorded on the SARMs certificates. The certificates referred to SARM 20 as low rank subbituminous coal (low carbon content) and SARM 18 as bituminous (high carbon content). Therefore, the low recoveries of REEs in SARM 20 might be due to the strong interaction between REEs and the minerals of the coal, since SARM 20 has 1:1 ration of carbon and mineral contents. These findings are also supported by previously published reports $[10,37]$.

The coal samples (CSA, CSB, and CSC) were also subjected to MAA and showed weight losses ranging between 67.45 and $83.04 \%$, suggesting more carbon content, as observed in the case of SARMs 18 and 19. Therefore, the investigated coal samples have similar properties of high-volatile low ranked bituminous coal with high carbon content. Form the results presented in Figure 6 and Table 3, it can be concluded that the proposed MAA-UAE method is suitable for quantitative analysis REEs in coal sample with high carbon content coals like bituminous. 
Table 3. Coal CRM percentage weight loses after MAA in replicates $(n=3)$.

\begin{tabular}{ccccc}
\hline CRM & $\begin{array}{c}\text { Average Weight } \\
\text { before Ashing } \\
\text { (AWBA) (g) }\end{array}$ & $\begin{array}{c}\text { Average Weight after } \\
\text { Ashing (AWAA) }(\mathbf{g})\end{array}$ & $\begin{array}{c}\text { Weight Difference } \\
\text { (AWBA) }- \text { (AWAA) } \\
\text { (g) }\end{array}$ & $\begin{array}{c}\text { Weight Loss (\%) } \\
\frac{(\text { AWBA)- }(\text { AWAA) }}{\text { AWB }} \times 100 \%\end{array}$ \\
\hline SARM 18 & $2.011(1.99)$ & $0.4991(2.65)$ & 1.5119 & 75.52 \\
SARM 19 & $2.009(1.86)$ & $0.7382(2.22)$ & 1.2708 & 63.52 \\
SARM 20 & $2.021(1.56)$ & $0.9820(2.95)$ & 1.0386 & 51.41 \\
CSA & $2.005(0.006)$ & $0.6252(0.018)$ & 1.3520 & 67.45 \\
CSB & $2.004(0.005)$ & $0.5404(0.047)$ & 1.3633 & 70.58 \\
CSC & $2.004(0.002)$ & $0.3399(0.012)$ & 1.6637 & 83.04 \\
\hline
\end{tabular}

Figures in parentheses are percentage relative standard deviation values (\%RSD). CSA: coal sample A, CSB: coal sample B, CSC: coal sample C.

\subsubsection{Analytical Figures of Merits}

The analytical response characteristics for REEs were obtained using SARM 19 and the optimized MAA-UAE method. Sensitivity (slope/gradient), correlation coefficient $\left(R^{2}\right)$, precision (\% RSD), recoveries, method limit of detection (MLOD), and method limit of quantification (MLOQ) are among the analytical performances investigated. Table 4 shows that REEs response functions have good sensitivity between (565.996 and $3.993 \mathrm{cps} \mathrm{L} \mathrm{\mu g}^{-1}$ ) for targeted REEs and a satisfactory coefficient of correlation $\left(R^{2}>0.9980\right)$. The proposed analytical procedure was more sensitive to $\mathrm{Sc}$ than to the other elements studied. Thus, the highest slope obtained for Sc was $565.996 \mathrm{cps} \mathrm{L} \mathrm{\mu g}^{-1}$, while the lowest slope obtained

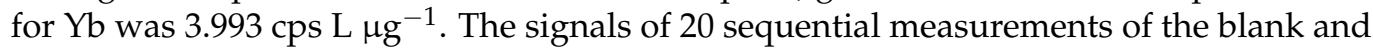
the slope (gradient) of the calibration curve were used to calculate the MLOD and MLOQ under optimal conditions. The MLOQs are defined as the lowest concentrations of analyte that produce a signal that is ten times the standard deviation (SD) of the blank signals multiplied by the dilution factor as shown in Equation (2). The MLODs, on the other hand, is defined as the lowest concentrations of analyte that produce a signal equal to three times the SD of the blank signal multiplied by the dilution factor, as shown in Equation (3). The equations for calculating MLOD and MLOQ are as follows:

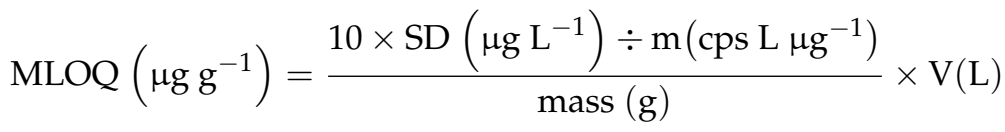

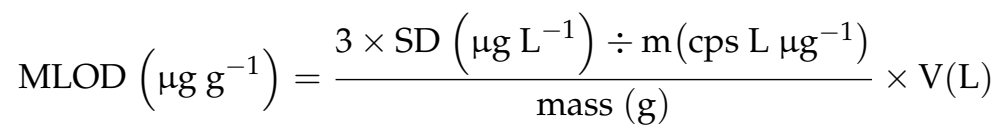

where SD is the standard deviation of 20 blank intensity signals, $\mathrm{m}$ is the slope/gradient of the calibration curve, $\mathrm{V}$ is the final volume in litres, and mass is the sample mass weighed in grams. The MLOD and MLOQ for the proposed MAA-UAE method were found to range between $\left(0.0075\right.$ and $\left.0.59 \mu \mathrm{g} \mathrm{g}^{-1}\right)$ and $\left(0.013\right.$ and $\left.1.96 \mu \mathrm{g} \mathrm{g}^{-1}\right)$, respectively (Table 4$)$. The MAA-UAE method was compared to other sample preparation methods used in geological and fossil fuel for the determination of REEs and results are represented in Table 5. From this table it can be observed that recoveries of the proposed method agree with some reported methods in the literature. In the case of detection, the detection limits of this method are slightly higher $\left(0.0075-0.59 \mu \mathrm{g} \mathrm{g}^{-1}\right)$ than those reported, but for kimberlite rock and geological samples detection limit are higher than those of proposed method, as they range between $\left(0.12-1.54 \mu \mathrm{g} \mathrm{g}^{-1}\right)$ and $\left(0.02-2.6 \mu \mathrm{g} \mathrm{g}^{-1}\right)$, respectively [38,39]. However, most of the methods in the table used multiple concentrated reagents, which might cause secondary pollution. The proposed method enhanced extraction using very dilute $\mathrm{HNO}_{3}$ $\left(1 \mathrm{~mol} \mathrm{~L}^{-1}\right)$. Moreover, ultrasound waves generate a phenomenon known as "cavitation bubbles" when waves propagate trough a liquid material medium. Then, due to a series of cycles of rarefaction and compression, the bubbles collapse. As a result of this cavitation phenomena, the solvent penetrates more deeply into the sample material, which may be 
explained by the larger surface area of contact between both solid and liquid phases, and thus is an improvement of the annual transfer process [40]. The precision of the proposed method was found to be less than $5 \%(n=6)$, while some of the other literature work reported precision of more than $5 \%[29,38,41]$. This implies that the proposed MAA-UAE method was highly reproducible.

Table 4. Analytical figures of merits of the MAA-UAE for REEs in SARM 19. UAE conditions: $\left[\mathrm{HNO}_{3}\right]\left(1 \mathrm{~mol} \mathrm{~L}^{-1}\right)$, sample mass $(0.1 \mathrm{~g})$, extraction time $(20 \mathrm{~min}), \mathrm{UAE}$ temperature $\left(80^{\circ} \mathrm{C}\right)$, UAE frequency (high), and replicates $(n=3)$.

\begin{tabular}{|c|c|c|c|c|c|}
\hline Element & $\begin{array}{l}\text { Sensitivity } \\
\left(\mathrm{L} \mu \mathrm{g}^{-1}\right)\end{array}$ & $\begin{array}{l}\text { Correlation } \\
\text { Coefficient } \\
\qquad\left(\mathbf{R}^{2}\right)\end{array}$ & $\begin{array}{l}\text { MLOD }^{a} \\
\left(\mu g g^{-1}\right)\end{array}$ & $\begin{array}{c}\operatorname{MLOQ}^{b} \\
\left(\mu g g^{-1}\right)\end{array}$ & $\begin{array}{c}\text { Precision } \\
\text { (Intraday) } \\
(\%)\end{array}$ \\
\hline Cerium (Ce) & 22.430 & 0.9993 & 0.089 & 0.29 & 3.285 \\
\hline Europium (Eu) & 183.392 & 0.9992 & 0.0075 & 0.025 & 2.96 \\
\hline Lanthanum (La) & 75.943 & 0.9985 & 0.03 & 0.093 & 3.458 \\
\hline Samarium (Sm) & 42.060 & 0.9992 & 0.14 & 0.46 & 2.509 \\
\hline Scandium (Sc) & 565.996 & 0.9999 & 0.0039 & 0.013 & 3.053 \\
\hline Yttrium (Y) & 47.692 & 0.9998 & 0.057 & 0.19 & 3.008 \\
\hline Ytterbium (Yb) & 3.993 & 0.9985 & 0.59 & 1.96 & 4.805 \\
\hline Terbium (Tb) & 44.597 & 0.9980 & 0.046 & 0.15 & 3.655 \\
\hline
\end{tabular}

a MLOD: method limit of detection, ${ }^{\mathrm{b}}$ MLOQ: method limit of quantification.

Table 5. Comparison of MAA-UAE analytical figures of merit with literature related sample preparation methods.

\begin{tabular}{|c|c|c|c|c|c|c|c|c|c|}
\hline Sample & $\begin{array}{l}\text { Digestion } \\
\text { Method }\end{array}$ & $\begin{array}{c}\text { Sample Preparation } \\
\text { Remarks }\end{array}$ & $\begin{array}{l}\text { Detection } \\
\text { Technique }\end{array}$ & Elements & $\begin{array}{l}\text { MLOD } \\
\left(\mu g^{-1}\right)\end{array}$ & $\begin{array}{c}\text { Accuracy } \\
(\%)\end{array}$ & $\begin{array}{l}\text { Precision } \\
\quad(\%)\end{array}$ & $\begin{array}{l}\text { Time } \\
\text { (Hour) }\end{array}$ & Ref. \\
\hline $\begin{array}{l}\text { Heavy crude } \\
\text { oil }\end{array}$ & MAD-SRC & $\begin{array}{c}500 \mathrm{mg}, \mathrm{HNO}_{3}(5 \mathrm{~mL}) \\
+\mathrm{H}_{2} \mathrm{O}_{2} \\
(1 \mathrm{~mL}) \text { and } 220^{\circ} \mathrm{C}\end{array}$ & USN-ICP-MS & $\begin{array}{l}\mathrm{Ce}, \mathrm{Dy}, \mathrm{Er} \\
\mathrm{Eu}, \mathrm{Gd}, \mathrm{Ho}, \\
\mathrm{La}, \mathrm{Lu}, \mathrm{Nd}, \\
\mathrm{Pr}, \mathrm{Sm}, \mathrm{Tb} \\
\mathrm{Tm}, \mathrm{Y}, \mathrm{Yb}\end{array}$ & 0.00003-0.0006 & $94-110$ & NR & 1 & [27] \\
\hline $\begin{array}{l}\text { Kimberlite } \\
\text { Rock }\end{array}$ & & $\begin{array}{l}0.2 \mathrm{~g}, \mathrm{Na}_{2} \mathrm{O}_{2}(1.5 \mathrm{~g}) \\
\text { and then dissolved in } \\
\text { water and } \mathrm{HCl}\end{array}$ & & $\begin{array}{l}\text { Y, La, Ce, Pr, } \\
\text { Sm, Eu, Gd, } \\
\text { Tb, Dy, Ho, } \\
\text { Er, Tm, Yb, } \\
\quad \text { Lu }\end{array}$ & $0.12-1.54$ & NR & $<14$ & NR & [38] \\
\hline Crude oil & MAD-UV & $\begin{array}{c}500 \mathrm{mg}, \\
\left(\mathrm{HNO}_{3}+\mathrm{H}_{2} \mathrm{O}_{2}\right) \\
(10 \mathrm{~mL}) \text { and } 220{ }^{\circ} \mathrm{C}\end{array}$ & USN-ICP-MS & $\begin{array}{c}\text { La, Ce, Pr, } \\
\text { Nd, Sm, Eu, } \\
\text { Gd, Tb, Dy, } \\
\text { Ho, Er, Tm, } \\
\text { Yb, Lu, Y }\end{array}$ & $0.00009-0.0006$ & $97-102$ & NR & 1 & [42] \\
\hline $\begin{array}{l}\text { Ultramafic } \\
\text { rock }\end{array}$ & HPD & $\begin{array}{c}\text { Step 1: } 0.2 \mathrm{~g}, \mathrm{HF} \\
0.5(\mathrm{~mL})+\mathrm{HNO}_{3} \\
(0.5 \mathrm{~mL}) \text {, and } 150{ }^{\circ} \mathrm{C} \\
\text { Step } 2: \mathrm{HF}(0.5 \mathrm{~mL}), \\
\text { and heated to dryness, } \\
\text { then, heated } 190^{\circ} \mathrm{C} \text { in } \\
\left(\mathrm{HF}(0.2 \mathrm{~mL})+\mathrm{HNO}_{3}\right. \\
(2 \mathrm{~mL}) \text { and } 190^{\circ} \mathrm{C}\end{array}$ & ICP-MS & $\begin{array}{l}\text { Y, La, Ce, Pr, } \\
\text { Nd, Sm, Eu, } \\
\text { Gd, Tb, Dy, } \\
\text { Ho, Er, Er, } \\
\text { Tm, Yb, Lu }\end{array}$ & $0.00003-0.00051$ & 93-102 & NR & 36 & [43] \\
\hline $\begin{array}{l}\text { Geological } \\
\text { samples }\end{array}$ & MAD & $\begin{array}{c}\text { Step 1: } 50 \mathrm{mg}, \mathrm{HNO}_{3} \\
(5 \mathrm{~mL})+\mathrm{HF}(2 \mathrm{~mL}) \\
\text { and } 240^{\circ} \mathrm{C} \\
\text { Step 2: } \mathrm{HNO}_{3},(5 \mathrm{~mL}) \\
\text { and } 180^{\circ} \mathrm{C}\end{array}$ & ICP-MS & $\mathrm{Eu}$ & 0.000006 & 97.24 & 0.923 & 5.25 & [44] \\
\hline $\begin{array}{l}\text { Geological } \\
\text { Rock }\end{array}$ & MAD & $\begin{array}{l}100 \mathrm{mg} \text {, aqua regia, } \\
(9 \mathrm{~mL}) \text { and } 220^{\circ} \mathrm{C}\end{array}$ & SVDV-ICP-OE & $\begin{array}{l}\text { La, Ce, Pr, } \\
\text { Nd, Sm, Eu } \\
\text { Gd, Tb, Dy, } \\
\text { Ho, Er, Tm, } \\
\text { Yb, Lu }\end{array}$ & $0.02-2.6$ & $90-107$ & $<5$ & 0.66 & [39] \\
\hline $\begin{array}{l}\text { Geological } \\
\text { sample }\end{array}$ & HPD & $\begin{array}{c}250 \mathrm{mg}, \mathrm{HCl}+\mathrm{HNO}_{3} \\
+\mathrm{HF} \text { and } 110^{\circ} \mathrm{C}\end{array}$ & ICP-OES & $\begin{array}{l}\mathrm{La}, \mathrm{Nd}, \mathrm{Eu}, \\
\mathrm{Gd}, \mathrm{Dy}, \mathrm{Er}, \\
\mathrm{Yb}\end{array}$ & $0.0003-0.0067$ & $92-112$ & $<7$ & 6 & [29] \\
\hline $\begin{array}{l}\text { Graphite } \\
\text { mineral }\end{array}$ & MAD & $\begin{array}{l}\mathrm{HNO}_{3}(5 \mathrm{~mL}) \text { and } \\
\mathrm{H}_{2} \mathrm{O}_{2}(1 \mathrm{~mL})\end{array}$ & USN-ICP-MS & $\begin{array}{l}\mathrm{Ce}, \mathrm{Eu}, \mathrm{Gd}, \\
\mathrm{La}, \mathrm{Lu}, \mathrm{Pr}, \\
\text { Sm }\end{array}$ & $0.00006-0.018$ & $<100.2$ & $<24$ & 1 & [41] \\
\hline
\end{tabular}


Table 5. Cont.

\begin{tabular}{|c|c|c|c|c|c|c|c|c|c|}
\hline Sample & $\begin{array}{l}\text { Digestion } \\
\text { Method }\end{array}$ & $\begin{array}{c}\text { Sample Preparation } \\
\text { Remarks }\end{array}$ & $\begin{array}{l}\text { Detection } \\
\text { Technique }\end{array}$ & Elements & $\begin{array}{l}\text { MLOD } \\
\left(\mu g g^{-1}\right)\end{array}$ & $\begin{array}{l}\text { Accuracy } \\
(\%)\end{array}$ & $\begin{array}{l}\text { Precision } \\
(\%)\end{array}$ & $\begin{array}{l}\text { Time } \\
\text { (hour) }\end{array}$ & Ref. \\
\hline Crude oil & MIC & $\begin{array}{c}250 \mathrm{mg} \text { and } 1400 \text { with } \\
20 \text { bar of oxygen and } \\
50 \text { mL of } 6 \mathrm{M} \\
\text { ammonium nitrate } \\
\mathrm{NH}_{4} \mathrm{NO}_{3} \text { as igniter }\end{array}$ & USN-ICP-MS & $\begin{array}{c}\text { La, Ce, Pr, } \\
\text { Nd, Sm, Eu, } \\
\text { Gd, Tb, Dy, } \\
\text { Ho, Er, Tm, } \\
\text { Yb, Lu, Y }\end{array}$ & $0.00018-0.00153$ & 97.8-102 & $<5$ & 5 & [45] \\
\hline Coal & MAA-UAE & $\begin{array}{c}\text { Ashed at } 550{ }^{\circ} \mathrm{C} \text {, } \\
\text { extracted at } 40^{\circ} \mathrm{C} \text {, in } \\
\left(1 \mathrm{~mol} \mathrm{~L}^{-1}\right) \mathrm{HNO}_{3} \text {, for } \\
20 \mathrm{~min} \text { at high } \\
\text { frequency. }\end{array}$ & ICP-OES & $\begin{array}{c}\mathrm{Ce}, \mathrm{Eu}, \mathrm{La}, \\
\mathrm{Sc}, \mathrm{Sm}, \mathrm{Tb}, \mathrm{Y} \\
\mathrm{Yb}\end{array}$ & $0.0075-0.59$ & $92-120$ & $<5$ & 4.25 & $\begin{array}{l}\text { Current } \\
\text { study }\end{array}$ \\
\hline
\end{tabular}

MAD: microwave assisted digestion, HPD: hotplate digestion, MIC: microwave induced combustion, MAD-UV: microwave-assisted digested ultraviolet, MAD-SRC: microwave-assisted digestion single reaction chamber, MAA-UAE: microwave assisted ashing ultrasound assisted extraction, SVDV-ICP-OES: synchronous vertical dual view inductively coupled plasma optical emission spectrometry, USN-ICPOES: ultrasonic nebulizer system inductively coupled plasma optical emission spectrometry, ICP-MS: inductively coupled plasma mass spectrometry, ICP-OES: inductively coupled plasma optical spectrometry.

\subsection{Application of MAD-UAE Method in Real Coal Samples}

The optimized and validated MAD-UAE method was applied for the quantitative extraction of REEs in three coal samples obtained from one of the South African coal mines. The coal samples were abbreviated as coal A, B, and C (CSA, CSB, and CSC, respectively). The results for this investigation are concentration levels obtained as presented in Table 6. A trend was observed for concentration levels of REEs, where several elements in CSA and CSB were not detected as compared to CSC, where every element was detected. Furthermore, CSC had the highest concentration levels of REEs, while coal sample A and B contained similar concentration levels, but coal sample A had slightly low concentration levels. For CSA and CSB elements such as Ce, Eu, La, Pr, Sm, Sc, and Tm were not detected. The solution to this will be the use of more sensitive detection technique, like ICP-MS. In the case of CSC, all targeted elements were detected, and the most dominant elements were $\mathrm{Ce}, \mathrm{La}, \mathrm{Nd}, \mathrm{Y}, \mathrm{Pr}$, and $\mathrm{Ho}$, according to analytical results reported within 22 and $105 \mu \mathrm{g} \mathrm{g}^{-1}$ (Table 6). Elements $\mathrm{Yb}, \mathrm{Er}, \mathrm{Eu}, \mathrm{Tb}$ and $\mathrm{Lu}$, on the other hand, were only found in very small amounts ranging between 1 and $4 \mu \mathrm{g} \mathrm{g}^{-1}$. The concentration levels of the other REEs ranged from 7 to $9 \mu \mathrm{g} \mathrm{g}^{-1}$. The REE concentrations in CSC were increasing in the following order: $\mathrm{Lu}<\mathrm{Tb}<\mathrm{Eu}<\mathrm{Er}<\mathrm{Yb}<\mathrm{Gd}<\mathrm{Sm}<\mathrm{Sc}<\mathrm{Ho}<\mathrm{Pr}<\mathrm{Y}<\mathrm{Nd}<\mathrm{La}<\mathrm{Ce}$ The relative standard deviation ( $\%$ RSD) across the three coal samples was $\leq 5 \%$, indicating that the developed method was repeatable. From these results, it can be concluded that the proposed method was effective enough to extract REEs in coal samples.

Table 6. Concentration levels of REEs in three South African coal samples obtained by using MAAUAE followed by ICP-OES), $n=3$.

\begin{tabular}{|c|c|c|c|}
\hline Element & $\begin{array}{c}\text { Coal Sample A } \\
\left(\mu g g^{-1}\right)\end{array}$ & $\begin{array}{c}\text { Coal Sample B } \\
\left(\mu g g^{-1}\right)\end{array}$ & $\begin{array}{c}\text { Coal Sample C } \\
\left(\mu g g^{-1}\right)\end{array}$ \\
\hline Cerium (Ce) & $<\mathrm{ND}$ & $<\mathrm{ND}$ & $104.369(1.22)$ \\
\hline Europium (Eu) & $<\mathrm{ND}$ & $<\mathrm{ND}$ & $1.644(4.46)$ \\
\hline Erbium (Er) & $0.266(3.78)$ & $0.272(1.69)$ & $3.11(1.87)$ \\
\hline Gadolinium (Gd) & $0.382(4.14)$ & $0.44(2.62)$ & $7.13(0.34)$ \\
\hline Holmium (Ho) & $0.954(4.40)$ & $0.979(2.93)$ & $22.261(2.67)$ \\
\hline Lanthanum (La) & $<\mathrm{ND}$ & $<\mathrm{ND}$ & $54.989(2.626)$ \\
\hline Lutetium (Lu) & 1.109 (3.98) & $1.32(4.75)$ & $1.330(4.85)$ \\
\hline Neodymium (Nd) & $1.24(4.40)$ & $1.34(4.687)$ & $43.63(3.81)$ \\
\hline Praseodymium (Pr) & $<\mathrm{ND}$ & $<\mathrm{ND}$ & $30.44(3.98)$ \\
\hline Samarium (Sm) & $<\mathrm{ND}$ & $<\mathrm{ND}$ & $7.163(3.15)$ \\
\hline Scandium (Sc) & $<\mathrm{ND}$ & $<\mathrm{ND}$ & $8.928(2.42)$ \\
\hline Yttrium (Y) & $0.111(2.985)$ & $0.133(4.988)$ & $31.463(2.835)$ \\
\hline Ytterbium (Yb) & $1.047(3.018)$ & $1.609(1.53)$ & $3.462(1.658)$ \\
\hline Terbium (Tb) & $0.0695(2.147)$ & $0.0796(3.31)$ & $1.459(3.131)$ \\
\hline Thulium (Tm) & $<\mathrm{ND}$ & $<\mathrm{ND}$ & $4.67(4.46)$ \\
\hline
\end{tabular}

Notes: Figures in parentheses are percentage relative standard deviation values (\%RSD). ND: not determined/below detection. 


\section{Conclusions}

The current work highlights the invention of a simple, simple, novel, sensitive, greener, and precise MAA-UAE approach for quantitative extraction of REEs in coal samples prior to ICP-OES analysis. Since the proposed method required only $1 \mathrm{~mol} \mathrm{~L}^{-1}$ of $\mathrm{HNO}_{3}$ to extract the REEs in coal samples, it can be concluded that it is environmentally friendly when compared to conventional acid digestion methods.

The proposed MAA-UAE method showed comparable detection limits $\left(0.0075-0.59 \mathrm{~g} \mathrm{~g}^{-1}\right)$ to most of the literature reports, satisfactory precision $(<5 \%)$ and acceptable accuracy $(86-120 \%)$ for all the investigated REEs in SARMs 18 and 19. However, poor extraction efficiencies $(28-70 \%)$ were observed when using SARM 20, except for $Y(117.48 \%)$. This is because SARM 20 is known to be low rank sub-bituminous to bituminous, the poor accuracy of MAA-UAE can be associated with strong interaction of REEs with kaolinite and quartz minerals of the coal.

The developed MAA-UAE method was applied in real samples. In coal sample $\mathrm{C}$, all the targeted REEs were detected with concentration levels ranging between 1.4-105 $\mathrm{gg} \mathrm{g}^{-1}$, proving the effectiveness of the developed method. The elements with the highest concentration levels were $\mathrm{Ce}, \mathrm{La}, \mathrm{Pr}$, and $\mathrm{Nd}$, with 104.369, 54.899, 30.44, and $43.63 \mathrm{\mu g} \mathrm{g}^{-1}$, respectively. In the case of CSA and CSB, concentration levels were very low, the highest concertation obtained was $1.647 \mu^{-1} \mathrm{~g}^{-1}$ for $\mathrm{Y}$, and other elements were reading below detection limits. In view of the above discussion, it can be concluded that the proposed MAA-UAE method can be considered as an alternative to conventional acid digestion methods for REEs determination in high carbon content coal samples.

Author Contributions: Conceptualization, N.M. and P.N.N.; methodology, software, validation, formal analysis, investigation, resources and data curation, all authors; writing-original draft preparation, M.C.Z.; writing-review and editing, N.M. and P.N.N.; visualization, all authors; supervision, P.N.N. and N.M.; project administration and funding acquisition, N.M. All authors have read and agreed to the published version of the manuscript.

Funding: This research was funded by South African National Research Foundation-THUTHUKA (113951), University of South Africa, Chemistry Department, Industrial Research (CSIR) HCDINTERBURSARY and University of Johannesburg.

Acknowledgments: The authors would like to acknowledge Department of Physics, Unisa for their microwave-assisted ashing system and anonymous coal mine for the coal samples.

Conflicts of Interest: The authors declare no conflict of interest.

\section{References}

1. Cao, S.; Zhou, C.; Pan, J.-H.; Liu, C.; Tang, M.; Ji, W.; Hu, T.; Zhang, N. Study on influence factors of leaching of rare earth elements from coal fly ash. Energy Fuels 2018, 32, 8000-8005. [CrossRef]

2. Zhang, W.; Noble, A.; Yang, X.; Honaker, R. A Comprehensive review of rare earth elements recovery from coal-related materials. Minerals 2020, 10, 451. [CrossRef]

3. Phuoc, T.X.; Wang, P.; McIntyre, D. Detection of rare earth elements in Powder River Basin sub-bituminous coal ash using laser-induced breakdown spectroscopy (LIBS). Fuel 2016, 163, 129-132. [CrossRef]

4. Kolker, A.; Scott, C.; Hower, J.C.; Vazquez, J.A.; Lopano, C.L.; Dai, S. Distribution of rare earth elements in coal combustion fly ash, determined by SHRIMP-RG ion microprobe. Int. J. Coal Geol. 2017, 184, 1-10. [CrossRef]

5. Wu, S.; Hong, W.; Zhang, B.; Yang, C.; Wang, J.; Gao, J.; Mi, F.; Zhang, H.; Zhao, X.; Li, Q. Study on the determination of rare earth elements in coal ash by ICP-MS. Integr. Ferroelectr. 2019, 198, 116-121. [CrossRef]

6. Krishna, M.V.B.; Venkateswarlu, G.; Karunasagar, D. Development of a simple and robust microwave-assisted decomposition method for the determination of rare earth elements in coal fly ash by ICP-OES. Anal. Methods 2017, 9, 2031-2040. [CrossRef]

7. Ardini, F.; Soggia, F.; Rugi, F.; Udisti, R.; Grotti, M. Comparison of inductively coupled plasma spectrometry techniques for the direct determination of rare earth elements in digests from geological samples. Anal. Chim. Acta 2010, 678, 18-25. [CrossRef]

8. Mello, P.; Pereira, J.S.F.; Mesko, M.F.; Barin, J.S.; Flores, E.M. Sample preparation methods for subsequent determination of metals and non-metals in crude oil-A review. Anal. Chim. Acta 2012, 746, 15-36. [CrossRef] [PubMed]

9. Wilschefski, S.C.; Baxter, M.R. Inductively coupled plasma mass spectrometry: Introduction to analytical aspects. Clin. Biochem. Rev. 2019, 40, 115-133. [CrossRef] 
10. Mketo, N.; Nomngongo, P.N.; Ngila, J. An innovative microwave-assisted digestion method with diluted hydrogen peroxide for rapid extraction of trace elements in coal samples followed by inductively coupled plasma-mass spectrometry. Microchem. J. 2016, 124, 201-208. [CrossRef]

11. Gholami, M.; Behkami, S.; Zain, M.G.S.B.S.M.; Bakirdere, S. A simple design for microwave assisted digestion vessel with low reagent consumption suitable for food and environmental samples. Sci. Rep. 2016, 6, 37186. [CrossRef]

12. Szymczycha-Madeja, A.; Welna, M.; Pohl, P. Simple and fast sample preparation procedure prior to multi-element analysis of slim teas by ICP OES. Food Anal. Methods 2014, 7, 2051-2063. [CrossRef]

13. Janski, R.; Neouze, M.-A.; Limbeck, A. Determination of rare earth elements in saline matrices using dispersed particle extraction and inductively coupled plasma mass spectrometry. Rapid Commun. Mass Spectrom. 2014, 28, 1329-1337. [CrossRef] [PubMed]

14. Mketo, N.; Nomngongo, P.N.; Ngila, J.C. An overview on analytical methods for quantitative determination of multi-element in coal samples. TrAC Trends Anal. Chem. 2016, 85, 107-116. [CrossRef]

15. Mketo, N.; Nomngongo, P.N.; Ngila, J.C. A rapid microwave-assisted acid extraction method based on the use of diluted $\mathrm{HNO}_{3}-\mathrm{H}_{2} \mathrm{O}_{2}$ followed by ICP-MS analysis for simultaneous determination of trace elements in coal samples. Int. J. Environ. Anal. Chem. 2015, 95, 453-465. [CrossRef]

16. Zhou, G.; Fu, L.; Li, X. Optimisation of ultrasound-assisted extraction conditions for maximal recovery of active monacolins and removal of toxic citrinin from red yeast rice by a full factorial design coupled with response surface methodology. Food Chem. 2015, 170, 186-192. [CrossRef]

17. Ferrarini, S.F.; Maia, S.M. Application of ultrasound-assisted extraction and heating combined with icp-oes for coal sample analysis. At. Spectrosc. 2013, 25, 103-156. [CrossRef]

18. Pontes, F.V.M.; Mendes, B.A.D.O.; De Souza, E.M.; Ferreira, F.N.; Da Silva, L.I.; Carneiro, M.C.; Monteiro, M.I.; De Almeida, M.D.; Neto, A.A.; Vaitsman, D.S. Determination of metals in coal fly ashes using ultrasound-assisted digestion followed by inductively coupled plasma optical emission spectrometry. Anal. Chim. Acta 2010, 659, 55-59. [CrossRef] [PubMed]

19. Nascentes, C.C.; Korn, M.; Arruda, M.A. A fast ultrasound-assisted extraction of Ca, Mg, Mn and $\mathrm{Zn}$ from vegetables. Microchem. J. 2001, 69, 37-43. [CrossRef]

20. Annegowda, H.V.; Bhat, R.; Min-Tze, L.; Karim, A.A.; Mansor, S.M. Influence of sonication treatments and extraction solvents on the phenolics and antioxidants in star fruits. J. Food Sci. Technol. 2012, 49, 510-514. [CrossRef]

21. Kenari, R.E.; Dehghan, B. Optimization of ultrasound-assisted solvent extraction of hemp (Cannabis sativa L.) seed oil using RSM: Evaluation of oxidative stability and physicochemical properties of oil. Food Sci. Nutr. 2020, 8, 4976-4986. [CrossRef]

22. Ni, Z.; Tang, F.; Liu, Y.; Shen, D.; Mo, R. Multielemental analysis of camellia oil by microwave dry ashing and inductively coupled plasma mass spectrometry. Anal. Lett. 2015, 48, 1777-1786. [CrossRef]

23. Mohammed, E.; Mohammed, T.; Mohammed, A. Optimization of an acid digestion procedure for the determination of $\mathrm{Hg}$, As, $\mathrm{Sb}, \mathrm{Pb}$ and $\mathrm{Cd}$ in fish muscle tissue. MethodsX 2017, 4, 513-523. [CrossRef]

24. Uddin, A.H.; Khalid, R.S.; Alaama, M.; Abdualkader, A.M.; Kasmuri, A.; Abbas, S.A. Comparative study of three digestion methods for elemental analysis in traditional medicine products using atomic absorption spectrometry. J. Anal. Sci. Technol. 2016, 7, 1. [CrossRef]

25. Sastre, J.; Sahuquillo, A.; Vidal, M.; Rauret, G. Determination of Cd, Cu, Pb and $\mathrm{Zn}$ in environmental samples: Microwave-assisted total digestion versus aqua regia and nitric acid extraction. Anal. Chim. Acta 2002, 462, 59-72. [CrossRef]

26. Mketo, N.; Ngila, J.C. Development of Microwave Based Sample Preparation Methods for Extraction of Multi-Element for Coal Clean-Up and Spectrometric Determination; ProQuest Dissertations Publishing: Ann Arbor, MI, USA, 2016.

27. Druzian, G.T.; Pereira, L.S.F.; Mello, P.; Mesko, M.F.; Duarte, F.; Flores, E.M.M. Rare earth element determination in heavy crude oil by USN-ICP-MS after digestion using a microwave-assisted single reaction chamber. J. Anal. At. Spectrom. 2016, 31, 1185-1191. [CrossRef]

28. Fariñas, J.C.; Rucandio, I.; Pomares-Alfonso, M.S.; Villanueva-Tagle, M.E.; Larrea, M.T. Determination of rare earth and concomitant elements in magnesium alloys by inductively coupled plasma optical emission spectrometry. Talanta 2016, 154, 53-62. [CrossRef]

29. Guimarães-Silva, A.K.; De Lena, J.C.; Froes, R.; Costa, L.M.; Nascentes, C.C. Evaluation of signal-to-background and Mg II/Mg I ratios as response for the optimization of rare earth elements determination by inductively coupled plasma optical emission spectrometry. J. Braz. Chem. Soc. 2012, 23, 753-762. [CrossRef]

30. Mketo, N.; Nomngongo, P.N.; Ngila, J.C. Development of a novel and green microwave-assisted hydrogen peroxide digestion method for total sulphur quantitative extraction in coal samples prior to inductively coupled plasma-optical emission spectroscopy and ion-chromatography determination. RSC Adv. 2015, 5, 38931-38938. [CrossRef]

31. Masanabo, N.M.; Zinyemba, O.; Mketo, N. A greener microwave-assisted extraction method for rapid spectroscopic determination of selected metals in river and freshwater sediment certified reference materials. Int. J. Environ. Anal. Chem. 2019, 99, 33-46. [CrossRef]

32. Maran, J.P.; Mekala, V.; Manikandan, S. Modeling and optimization of ultrasound-assisted extraction of polysaccharide from Cucurbita moschata. Carbohydr. Polym. 2013, 92, 2018-2026. [CrossRef]

33. Ghitescu, R.-E.; Volf, I.; Carausu, C.; Bühlmann, A.-M.; Gilca, I.A.; Popa, V.I. Optimization of ultrasound-assisted extraction of polyphenols from spruce wood bark. Ultrason. Sonochem. 2015, 22, 535-541. [CrossRef] 
34. Liao, J.; Zheng, N.; Qu, B. An improved ultrasonic-assisted extraction method by optimizing the ultrasonic frequency for enhancing the extraction efficiency of lycopene from tomatoes. Food Anal. Methods 2016, 9, 2288-2298. [CrossRef]

35. Chen, Q.-H.; Fu, M.-L.; Liu, J.; Zhang, H.-F.; He, G.-Q.; Ruan, H. Optimization of ultrasonic-assisted extraction (UAE) of betulin from white birch bark using response surface methodology. Ultrason. Sonochem. 2009, 16, 599-604. [CrossRef]

36. Wang, H.-J.; Pan, M.-C.; Chang, C.-K.; Chang, S.-W.; Hsieh, C. Optimization of ultrasonic-assisted extraction of cordycepin from cordyceps militaris using orthogonal experimental design. Molecules 2014, 19, 20808-20820. [CrossRef] [PubMed]

37. Mketo, N.; Nomngongo, P.N. An improved microwave assisted sequential extraction method followed by spectrometric analysis for metal distribution determination in South African coal samples. Sci. Rep. 2020, 10, 1-11. [CrossRef] [PubMed]

38. Kumar, S.A.; Pandey, S.P.; Kumar, S.D. Determination of rare earth elements in Indian kimberlite using inductively coupled plasma mass spectrometer (ICP-MS). J. Radioanal. Nucl. Chem. 2012, 294, 419-424. [CrossRef]

39. Amaral, C.D.B.; Machado, R.C.; Virgilio, A.; Schiavo, D.; Nogueira, A.R.A.; Nobrega, A. Determination of Rare Earth Elements in Geological Samples Using the Agilent SVDV ICP-OES; Agilent Technologies: Santa Clara, CA, USA, 2016; pp. 1-6.

40. Bang, J.H.; Suslick, K.S. Applications of ultrasound to the synthesis of nanostructured materials. Adv. Mater. 2010, 22, 1039-1059. [CrossRef] [PubMed]

41. Mello, P.A.; Pedrotti, M.F.; Cruz, S.M.; Muller, E.I.; Dressler, V.L.; Flores, E. Determination of rare earth elements in graphite by solid sampling electrothermal vaporization-inductively coupled plasma mass spectrometry. J. Anal. At. Spectrom. 2015, 30, 2048-2055. [CrossRef]

42. Pereira, J.S.F.; Mello, P.; Guimarães, R.; Guarnieri, R.; Fonseca, T.; Flores, E. Microwave-induced combustion of crude oil for further rare earth elements determination by USN-ICP-MS. Anal. Chim. Acta 2014, 844, 8-14. [CrossRef]

43. Sun, Y.; Sun, S.; Wang, C.Y.; Xu, P. Determination of rare earth elements and thorium at nanogram levels in ultramafic samples by inductively coupled plasma-mass spectrometry combined with chemical separation and pre-concentration. Geostand. Geoanal. Res. 2013, 37, 65-76. [CrossRef]

44. Yan, X.; Dai, S.; Graham, I.T.; He, X.; Shan, K.; Liu, X. Determination of Eu concentrations in coal, fly ash and sedimentary rocks using a cation exchange resin and inductively coupled plasma mass spectrometry (ICP-MS). Int. J. Coal Geol. 2018, 191, 152-156. [CrossRef]

45. Silva, J.; Henn, A.S.; Dressler, V.L.; Mello, P.A.; Flores, E.M.M. Feasibility of rare earth element determination in low concentration in crude oil: Direct sampling electrothermal vaporization-inductively coupled plasma mass spectrometry. Anal. Chem. 2018, 90, 7064-7071. [CrossRef] [PubMed] 